\title{
Prospective study of maternal outcomes in primigravida with gestational diabetes mellitus in a tertiary care centre, Venjaramood, Thiruvananthapuram
}

\author{
Lency S. Kuriakose, Bhavani L. Nair*, Prameeda P. Radha
}

\begin{abstract}
Department of Obstetrics and Gynaecology, Sree Gokulam Medical College and Research Foundation, Venjaramood, Thiruvananthapuram, Kerala, India
\end{abstract}

Received: 08 December 2021

Revised: 17 December 2021

Accepted: 23 December 2021

\author{
*Correspondence: \\ Dr. Bhavani L. Nair, \\ E-mail: bhavnair2003@gmail.com
}

Copyright: () the author(s), publisher and licensee Medip Academy. This is an open-access article distributed under the terms of the Creative Commons Attribution Non-Commercial License, which permits unrestricted non-commercial use, distribution, and reproduction in any medium, provided the original work is properly cited.

\begin{abstract}
Background: The prevalence of Gestational diabetes mellitus (GDM) is on the rise. Understanding the various outcomes of it is essential to face this challenge. The aim of the study was to understand the maternal outcomes of GDM in primigravida and to compare the maternal outcomes in primigravida with GDM and without GDM.

Methods: This prospective study was conducted in the department of obstetrics and gynaecology at Sree Gokulam Medical College and Research Foundation, Venjaramood, Thiruvananthapuram, on 180 primigravida mothers, 90 with and 90 without gestational diabetes. GDM was diagnosed with IADPSG criteria using $75 \mathrm{~g}$ Oral glucose tolerance test (OGTT).

Results: A total of 180 primigravida with singleton gestation, 90 with GDM and 90 without GDM were followed from pregnancy to delivery after fulfilling criteria during study period. 65.6\% GDM mothers had good compliance with Medical nutrition therapy (MNT) and exercise. 88.8\% of GDM mothers required induction of labour, $13.3 \%$ had pregnancy induced hypertension, $12.2 \%$ had vulvovaginal candidiasis and $10 \%$ had postpartum hemorrhage. Thus, women with GDM on MNT or MNT with insulin had a higher risk of adverse maternal outcomes but was comparable to normoglycemic mothers if they had good compliance to MNT or insulin.

Conclusions: Women with GDM had a higher but comparable risk of adverse maternal outcomes as compared to normoglycemic pregnant mothers, if they strictly adhere to MNT with or without insulin reflecting the importance of good treatment compliance.
\end{abstract}

Keywords: Gestational diabetes mellitus, 75 g OGTT, Medical nutrition therapy, Insulin

\section{INTRODUCTION}

Diabetes represents a spectrum of metabolic disorders, which has become a major health challenge worldwide. The unprecedented economic development and rapid urbanization in Asian countries, particularly in India has led to a shift in health problems from communicable to non-communicable diseases. Of all the non-communicable diseases, diabetes and cardiovascular diseases lead the list. The prevalence of diabetes is increasing globally and the total number of people with this condition is projected to rise from 171 million in 2000 to 552 million in 2030 as per International Diabetes Federation. India is no exception, with projected rates of estimated 100 million in 2030. The International Diabetes Federation estimated that 72.9 million adults had diabetes in India in 2017. The increased prevalence is attributed to the aging population structure, urbanization, the obesity epidemic and physical inactivity.

While all these factors contribute to the epidemic of diabetes, intrauterine exposures are emerging as potential risk factors. The fetal origin of adult disease hypothesis 
proposes that gestational programming may critically influence adult health and disease. ${ }^{1}$

Gestational programming is a process whereby stimuli or stresses occurring at critical or sensitive periods of fetal development, permanently change structure, physiology and metabolism, which predisposes individuals to disease in adult life. If the stimulus is glucose intolerance in pregnancy, it predisposes the offspring to an increased risk of developing glucose intolerance in the future. This vicious cycle is likely to influence and perpetuate the incidence and prevalence of glucose intolerance in any population. ${ }^{2}$ Therefore, preventive measures against type 2 diabetes should start during intrauterine period and continue from early childhood throughout life. In this respect, detection of Gestational diabetes mellitus (GDM) becomes an important public health issue. The importance of GDM is that two generations are at risk of developing diabetes in future. Women with a history of GDM are at increased risk of future diabetes, predominantly type 2 diabetes, as are their children. ${ }^{3,4}$

GDM is defined as a glucose intolerance of varying degrees of severity with onset or first recognition during pregnancy and is associated with increased feto-maternal morbidity as well as long-term complications in mother and child. ${ }^{5-7}$ It develops when a stage is reached, when the pancreas despite the increased insulin production cannot counter the insulin resistance caused by pregnancy hormones. The present study was undertaken to study the maternal outcomes of GDM in primigravida and to compare the maternal outcomes in GDM primigravida with normoglycemic primigravida.

\section{METHODS}

This was a prospective study conducted at Sree Gokulam Medical College and Research Foundation, Venjaramood, Thiruvananthapuram. It included 180 primigravida ,90 each with and without GDM. The sample size was fixed by using formula for testing the difference between two proportions.

$$
N=\frac{2 p(1-p)(Z \propto+Z \beta)^{2}}{\left(p_{1}-p_{2}\right)^{2}}
$$

where $\alpha=0.05, \beta=0.2$

\section{Inclusion criteria}

The primigravida with singleton pregnancy were included.

\section{Exclusion criteria}

The primigravida with Type 1 diabetes, not detected GDM in early pregnancy, malpresentation, chronic diseases leading to fluid accumulation and appearance of protein in urine like congestive cardiac failure, chronic hypertension, preeclampsia, renal failure.
The primigravida satisfying the inclusion and exclusion criteria were subjected to $75 \mathrm{~g}$ Oral glucose tolerance test (OGTT) between 24 and 28 weeks gestation. Eligible mothers in both groups were consecutively recruited until sample size of 90 was achieved in each group.

GDM was diagnosed according to the International Association of Diabetes and Pregnancy Study Groups (IADPSG) Criteria done between 24-28 weeks of gestation. ${ }^{8}$ The diagnosis of GDM was confirmed if either Fasting blood glucose (FBG) was $\geq 92 \mathrm{mg} / \mathrm{dl}, 1$ hour blood glucose $\geq 180 \mathrm{mg} / \mathrm{dl}, 2$ hours blood glucose was $\geq 153$ $\mathrm{mg} / \mathrm{dl}$, following a $75 \mathrm{~g}$ OGTT.

Thus, only one abnormal value is essential to make the diagnosis of GDM. The results were made known to the mothers and their implications explained to them. Dietary control by Medical nutrition therapy (MNT), lifestyle modification, exercise (30 min brisk walk) and selfmonitoring of capillary blood glucose was advised. They were followed after 2 weeks with fasting and 1 hour post prandial blood glucose after a strict diet challenge (FBG $<95 \mathrm{mg} / \mathrm{dl}$, 1hour PPBG $<140 \mathrm{mg} / \mathrm{dl}$ ). The goals of MNT are to provide adequate nutrition for the mother and fetus, sufficient calories for appropriate maternal weight gain, maintain normoglycemia, avoid ketosis and postprandial hyperglycemia.

If despite lifestyle changes, glucose values remained above targets two or more times during a 1 to 2 -weeks period (FBG $>95 \mathrm{mg} / \mathrm{dl}, 1$ hour postprandial glucose $>140 \mathrm{mg} / \mathrm{dl}$ ), pharmacotherapy with insulin was introduced, depending on glucose values (i.e. insulin in case of relatively high values). The NICE guidelines recommend beginning pharmacological treatment if glycemic control is not achieved after 1-2 weeks of lifestyle changes. ${ }^{9}$

Short acting insulin analogues were adapted to achieve 1$\mathrm{hr}$ postprandial glucose $\leq 140 \mathrm{mg} / \mathrm{dl}$ or 2 -hr postprandial glucos $\leq 120 \mathrm{mg} / \mathrm{dl}$ and long acting insulin analogues to achieve $\mathrm{FBG}<95 \mathrm{mg} / \mathrm{dl}$.

The enrolled primigravida (180), 90 with GDM and 90 without GDM were followed up to labour and delivery during the study period. They were followed up during each of their antenatal visits with monitoring of blood glucose levels up to labour, for maternal outcomes with respect to following parameters. The antepartum variables were gestational hypertension, polyhydramnios, urinary tract infections, vulvovaginal candidiasis, preterm labour, elective induction rates. Intrapartum variables included mode of delivery, shoulder dystocia, Postpartum hemorrhage (PPH).

Statistic analysis was done using software SPSS Version 16. The statistical tests used included Chi square test. Chi square test was applied to find out the significance of association. $\mathrm{P}$ value of less than 0.05 was considered statistically significant. 


\section{Ethical consideration}

Signed informed consent was obtained from all participating women and permission was obtained from the Institutional Ethical Committee.

\section{RESULTS}

In our study, primigravida with GDM (study group) in the age group less than 30 years was 84 (93.4\%) and normoglycemic primigravida (control group) were 89 $(98.9 \%)$. Primigravida with GDM more than 30 years was $6(6.6 \%)$ and normoglycemic primigravida were $1(1.1 \%)$. $59(65.6 \%)$ GDM mothers had good glycemic control with MNT whereas 31 (34.4\%) mothers required MNT and insulin.

In comparison of the maternal complications in the GDM and normoglycemic mothers, it was found that $12(13.3 \%)$ GDM primigravida developed gestational hypertension compared to $11(12.2 \%)$ normoglycemic primigravidia. 12 $(13.3 \%)$ had polyhydramnios. $4(4.4 \%)$ in the study group had preterm labour compared to $6(6.6 \%)$ in the control group. Polyhydramnios was attributed as the cause of preterm labour here, infectious etiology being ruled out.
UTIs and vulvovaginal candidiasis were found to be 4 $(4.4 \%)$ and $11(12.2 \%)$ respectively in the study group whereas the same was found as $5(5.5 \%)$ and $3(3.3 \%)$ in the control group. $80(88.8 \%)$ in the study group had labour induction at 38-39 weeks whereas 55 (61.1\%) in the control group underwent labour induction.

This was statistically significant $\mathrm{p}$ value being 0.001 .

With respect to mode of delivery, in our study, 66 (73.3\%) underwent vaginal delivery against $70(77.7 \%)$ in the control group. $4(4.4 \%)$ had instrumental delivery in the study group as compared to $1(1.1 \%)$ in the control group. $20(22.2 \%)$ underwent cesarean section in GDM mothers as against $19(21.1 \%)$ in control group. Statistically, no significant difference was noted. $10 \%$ cases and $8 \%$ of controls had postpartum hemorrhage.

2 cases of shoulder dystocia were seen in GDM mothers and none in control group. There was 1 case of IUD in our study which was in a GDM mother at 36 weeks of gestation with reduced fetal movement, had umbilical cord 6 times around the neck. 1 IUD at 28 weeks was in control group which was unexplained.

Table 1: General characteristics of patients in two groups GDM and normoglycemic primigravida.

\begin{tabular}{|lll|}
\hline General characteristics & GDM primigravida & Normoglycemic primigravida \\
\hline Age distribution (years) & & $89(98.9 \%)$ \\
\hline$<30$ & $84(93.4 \%)$ & $1(1.1 \%)$ \\
\hline$>30$ & $6(6.6 \%)$ & \\
\hline Type of intervention & & \\
\hline MNT & $59(65.6 \%)$ & \\
\hline Insulin and MNT & $31(34.4 \%)$ & \\
\hline
\end{tabular}

Table 2: Comparing the maternal outcomes in GDM and normoglycemic primigravida.

\begin{tabular}{|llll|}
\hline Maternal complications & No. of GDM primigravida & $\begin{array}{l}\text { No. of normoglycemic } \\
\text { primigravida }\end{array}$ & P value \\
\hline Gestational hypertension & $12(13.3 \%)$ & $11(12.2 \%)$ & 0.52 \\
\hline Preterm labour & $4(4.4 \%)$ & $6(6.6 \%)$ & 0.373 \\
\hline Polyhydramnios & $12(13.3 \%)$ & $0(0 \%)$ & 0.001 (significant) \\
\hline Urinary tract infection & $4(4.4 \%)$ & $5(5.5 \%)$ & 0.082 \\
\hline Vulvovaginal candidiasis & $11(12.2 \%)$ & $3(3.3 \%)$ & 0.001 (significant) \\
\hline Labour induction & $80(88.8 \%)$ & $55(61.1 \%)$ & \\
\hline Mode of delivery & & & 0.378 \\
\hline Vaginal & $66(73.3 \%)$ & $70(77.7 \%)$ & \\
\hline Instrumental & $4(4.4 \%)$ & $1(1.1 \%)$ & $19(21.1 \%)$ \\
\hline Caesarean section & $20(22.2 \%)$ & & \\
\hline
\end{tabular}

\section{DISCUSSION}

In India, studies have reported varying prevalence of GDM from different parts of our country ranging from 3.8 to $21 \%$ as per geographic location and diagnostic criteria used. ${ }^{10} \mathrm{GDM}$ is estimated to affect nearly 5 million Indian women. Women diagnosed with GDM are at an increased risk of developing diabetes in future .It has implications beyond the index pregnancy identifying two generations for risk of development of future diabetes, cardiovascular disease and obesity. ${ }^{11,12}$ Previous studies on GDM have stated that untreated GDM is associated with higher rates of maternal and perinatal outcomes. ${ }^{13-15}$ Our study was done in a tertiary teaching hospital in Venjaramood, Thiruvananthapuram, after recruiting primigravida who met the inclusion and exclusion criteria. It highlights the 
importance of compliance and strict antenatal care in GDM mothers to prevent morbidity and mortality both for the mother and child.

In the present study primigravida were studied between age 18 and 35 years. The mean age of both study and control group were 24.24 years and 23.19 years respectively showing an increased prevalence of GDM in young population. Another study from South India by Bhatt et al found mean age in GDM mothers as 26.63 years and controls was 26.43 years. ${ }^{16}$

Almost $75-80 \%$ of patients with GDM can be managed with diabetic diet and lifestyle modifications. MNT is identified as "designing meals with controlled carbohydrate level for nutritional adequacy with normal nutrition, normal sugar levels and prevention of ketosis". ${ }^{17}$ Those with high blood sugars need pharmacological intervention like insulin, the most resorted approach by clinicians in India. Our study had 59 mothers $(65.5 \%)$ who were managed on MNT and 31 mothers (34.4\%) who required Insulin therapy in addition to MNT, which showed the good awareness and compliance to the principles of glycemic control in the population. A study by Kusagradhi et al showed $60.3 \%$ insulin requirement which was attributed to lack of awareness about glycemic control. ${ }^{18}$

In our study 12 cases (13.3\%) had gestational hypertension, no case of preeclampsia was there. In the comparative group $11(12.2 \%)$ were found to have gestational hypertension. Bhat Mamta et al showed significant association of gestational hypertension with GDM $29.3 \%$ in cases against $18.7 \%$ in controls. No case of gestational hypertension was reported in the study by Wahi et al. ${ }^{19}$

Polyhydramnios is defined sonologically as Amniotic fluid index (AFI) more than 25. The amniotic fluid volume is measured vertically in the deepest amniotic fluid pocket. Single deepest pocket over $8 \mathrm{~cm}$ indicates polyhydramnios. One possible explanation for this is fetal hyperglycemia resulting in increased osmotic diuresis which subsequently leads to polyuria in GDM. In our study, 12 cases $(13.33 \%)$ had high normal AFI (17 and above), which we took as cut off and tighter glycemic control offered to them by MNT or Insulin. No case was reported in control group, $\mathrm{p}$ value was significant $(0.001)$. Needless to emphasize that the other causes of polyhydramnios were ruled out. The study by Ghosh et al found incidence to be $5 \%$. Studies have shown an incidence of $5-26 \%$ of polyhydramnios which is comparable to the present study. ${ }^{20}$ Preterm labour was $4 \%$ in our study against $6(6.6 \%)$ in the comparative group. The study by Wahi et al found incidence of preterm births to be $4.2 \%$ in cases and $2.8 \%$ in controls.

Infections like urinary tract infection and vulvovaginal candidiasis were reported in $4.4 \%$ and $12.2 \%$ GDM mothers as against $5 \%$ and $3 \%$ in controls respectively.
The study by Ghosh et al reported incidence of UTI to be $8.6 \%$. All GDM patients whether on MNT or insulin therapy were induced at 39 or 38 completed weeks of gestation respectively in order to balance the increased risk of antepartum stillbirths and delayed lung maturity unless they went into spontaneous labour and controls were not allowed to go beyond 40 weeks. It was observed that GDM mothers had increased frequency of induced deliveries.88.8\% were induced deliveries and $6.6 \%$ had spontaneous labour. However, in controls $61.1 \%$ had induced labour against $38.9 \%$ who went into spontaneous labour. $p$ value was found significant $(0.001)$ in our study. Bhat Mamta et al observed increased frequency of induced deliveries as compared to spontaneous deliveries in GDM mothers.

With respect to mode of delivery, $22.2 \%$ underwent Cesarean Section in GDM mothers as against $21.1 \%$ in control group which is comparable in this study. The indication for caesarean section in GDM mothers were mainly failed induction and fetal distress. In contrast, Goldman et al reported an increased caesarean section rate of $35.3 \%$ in women with GDM as compared to $22 \%$ in those without it. ${ }^{21}$ In our study, $4.4 \%$ had instrumental delivery in the study group as compared to $1.1 \%$ in the control group. Statistically no significant difference was noted. With respect to the labour complications, $10 \%$ cases and $8 \%$ of controls had postpartum hemorrhage. Two cases of shoulder dystocia were seen in GDM mothers and none in control group. 1 case of IUD in our study was in a GDM mother at 36 weeks of gestation with reduced fetal movement, had umbilical cord 6 times around the neck. There was 1 IUD at 28 weeks in control group which was unexplained.

In our study, the comparable maternal outcomes observed in both groups could be because of the modest sample size, unlike the other studies where the complications are more in GDM mothers. We have also not studied the maternal outcomes of GDM if the mothers are taking Oral hypoglycemic agents like metformin.

\section{CONCLUSION}

Tight glycemic control antenatally drastically reduces the adverse outcomes which may be higher but comparable to normoglycemic mothers. It clearly reflects the importance of strict aggressive treatment of GDM mothers and good compliance to the treatment which was observed in the present study which can be attributed to the adherence to proper antenatal check-ups and to medical nutrition therapy or Insulin. Hence improvement of maternal care, screening for GDM and intervention strategies in women with GDM to reduce the obstetric complications and better the maternal outcomes is recommended.

\section{ACKNOWLEDGMENTS}

We are indebted to Dr. Kumari Beena, Head of Department, Department of Obstetrics and Gynaecology, 
Sree Gokulam Medical College and Research Foundation, Venjaramood, Thiruvananthapuram.

Funding: No funding sources

Conflict of interest: None declared

Ethical approval: The study was approved by the Institutional Ethics Committee

\section{REFERENCES}

1. Calkins K, Devaskar SU. Fetal origins of adult disease. Curr Probl Pediatr Adolescent Health Care. 2011;41(6):158-76.

2. Seshiah V, Balaji V, Balaji MS, Sanjeevi CB, Green A. Gestational diabetes mellitus in India. J Assoc Physicians India. 2004;52:707-11.

3. Svare JA, Hansen BB, Mølsted-Pedersen L. Perinatal complications in women with gestational diabetes mellitus. Acta Obstet Gynecol Scand. 2001;80(10):899-904.

4. Weindling A. Offspring of diabetic pregnancy: shortterm outcomes. Seminars Fetal Neonatal Med. 2009;14(2):111-8.

5. Seshiah V, Balaji V, Balaji MS, Paneerselvam A, Arthi T, Thamizharasi M, et al. Gestational diabetes mellitus manifests in all trimesters of pregnancy. Diabetes Res Clin Pract. 2007;77(3):482-4.

6. Seshiah V, Balaji V, Balaji MS, Paneerselvam A, Kapur A. Pregnancy and diabetes scenario around the world: India. Int J Gynaecol Obstet. 2009;104:35-8.

7. Bano S, Agrawal A, Asnani M, Das V, Singh R, Pandey A, et al. Correlation of Insulin Resistance in Pregnancy with Obstetric Outcome. J Obstet Gynaecol India. 2021;71(5):495-500.

8. International Association of Diabetes and Pregnancy Study Groups Consensus Panel, Metzger BE, Gabbe SG, Persson B, Buchanan TA, Catalano PA, et al. International association of diabetes and pregnancy study groups recommendations on the diagnosis and classification of hyperglycemia in pregnancy. Diabetes Care. 2010;33(3):676-82.

9. NICE. Diabetes in Pregnancy: Management from Preconception to Post natal period NICE Guideline, 2015. Available at: www.nice.org.uk/guidance/ng3. Accessed on 01 December 2021.

10. Seshiah V, Balaji V, Balaji MS, Paneerselvam A, Kapur A. Pregnancy and diabetes scenario around the world: India. Int J Gynaecol Obstet. 2009;104:35-8.
11. Bellamy L, Casas JP, Hingorani AD, Williams D. Type 2 diabetes mellitus after gestational diabetes: a systematic review and meta-analysis. Lancet. 2009;373(9677):1773-9.

12. Retnakaran R, Qi Y, Connelly PW, Sermer M, Zinman B, Hanley AJ. Glucose intolerance in pregnancy and postpartum risk of metabolic syndrome in young women. $\mathrm{J}$ Clin Endocrinol Metab. 2010;95(2):670-7.

13. Turok DK, Ratcliffe SD, Baxley EG. Management of gestational diabetes mellitus. Am Fam Physician. 2003;68(9):1767-72.

14. Mahalakshmi MM, Bhavadharini B, Maheswari K, Kalaiyarasi G, Anjana RM, Ranjit U, et al. Comparison of maternal and fetal outcomes among Asian Indian pregnant women with or without gestational diabetes mellitus: A situational analysis study (WINGS-3). Indian $\mathbf{J}$ Endocrinol Metab. 2016;20(4):491-6.

15. Shou C, Wei M, Wang C, Yang H. Updates in Longterm Maternal and Fetal Adverse Effects of Gestational Diabetes Mellitus. Maternal-Fetal Med. 2019;1(2):91-4.

16. Bhat M, Ramesha KN, Sarma SP, Menon S, Ganesh KS. Outcome of gestational diabetes mellitus from a tertiary referral center in South India: a case-control study. J Obstet Gynaecol India. 2012;62(6):644-9.

17. Peterson L, Peterson CM. Nutritional management of the obese gestational diabetic pregnant woman. J Am Coll Nutr. 1992;11(3):246-50.

18. Ghosh S, Ghosh K. Maternal and neonatal outcomes in gestational diabetes mellitus. J Indian Med Assoc. 2013;111(5):330-1.

19. Wahi P, Dogra V, Jandial K, Bhagat R, Gupta R, Gupta S, Wakhloo A, et al. Prevalence of gestational diabetes mellitus (GDM) and its outcomes in Jammu region. J Assoc Physicians India. 2011;59:227-30.

20. Hamza A, Herr D, Solomayer EF, Solomayer G. Polyhydramnios: Causes, Diagnosis and Therapy. Geburtshilfe Frauenheilkd. 2013;73(12):1241-6.

21. Goldman M, Kitzmiller JL, Abrams B, Cowan RM, Laros RK. Obstetric complications with GDM. Effects of maternal weight. Diabetes. 1991;40(2):7982.

Cite this article as: Kuriakose LS, Nair BL, Radha PP. Prospective study of maternal outcomes in primigravida with gestational diabetes mellitus in a tertiary care centre, Venjaramood,

Thiruvananthapuram. Int J Reprod Contracept Obstet Gynecol 2022;11:59-63. 